Sorina Gorcenco, MD

Jonna Komulainen-

Ebrahim, MD

Karin Nordborg, MD

Maria Suo-Palosaari, MD,

$\mathrm{PhD}$

Sten Andréasson, MD,

$\mathrm{PhD}$

Johanna Krüger, MD,

$\mathrm{PhD}$

Christer Nilsson, MD,

$\mathrm{PhD}$

Ulrika Kjellström, MD,

$\mathrm{PhD}$

Elisa Rahikkala, MD,

$\mathrm{PhD}$

Dominik Turkiewicz,

MD, PhD

Mikael Karlberg, MD,

$\mathrm{PhD}$

Lars Nilsson, $\mathrm{MD}, \mathrm{PhD}$

Jörg Cammenga, MD,

$\mathrm{PhD}$

Ulf Tedgård, $\mathrm{MD}, \mathrm{PhD}$

Josef Davidsson, MD,

$\mathrm{PhD}$

Johanna Uusimaa, MD,

$\mathrm{PhD}$

Andreas Puschmann, $\mathrm{MD}, \mathrm{PhD}$

Correspondence to

Dr. Puschmann:

Andreas.Puschmann@med.lu.se

\section{Supplemental data} at Neurology.org/ng

\title{
Ataxia-pancytopenia syndrome with SAMD9L mutations
}

\section{OPEN}

\section{ABSTRACT}

Objective: We describe the neurologic, neuroradiologic, and ophthalmologic phenotype of 1 Swedish and 1 Finnish family with autosomal dominant ataxia-pancytopenia (ATXPC) syndrome and SAMD9L mutations.

Methods: Members of these families with germline SAMD9L c.2956C $>$ T, p.Arg986Cys, or c.2672T>C, p.lle891Thr mutations underwent structured interviews and neurologic and ophthalmologic examinations. Neuroimaging was performed, and medical records were reviewed. Previous publications on SAMD9L-ATXPC were reviewed.

Results: Twelve individuals in both families were affected clinically. All mutation carriers examined had balance impairment, although severity was very variable. All but 1 had nystagmus, and all but 1 had pyramidal tract signs. Neurologic features were generally present from childhood on and progressed slowly. Two adult patients, who experienced increasing clumsiness, glare, and difficulties with gaze fixation, had paracentral retinal dysfunction verified by multifocal electroretinography. Brain MRI showed early, marked cerebellar atrophy in most carriers and variable cerebral periventricular white matter T2 hyperintensities. Two children were treated with hematopoietic stem cell transplantation for hematologic malignancies, and the neurologic symptoms of one of these worsened after treatment. Three affected individuals had attention deficit hyperactivity disorder or cognitive problems. Retinal dysfunction was not previously reported in individuals with ATXPC.

Conclusions: The neurologic phenotype of this syndrome is defined by balance or gait impairment, nystagmus, hyperreflexia in the lower limbs and, frequently, marked cerebellar atrophy. Paracentral retinal dysfunction may contribute to glare, reading problems, and clumsiness. Timely diagnosis of ATXPC is important to address the risk for severe hemorrhage, infection, and hematologic malignancies inherent in this syndrome; regular hematologic follow-up might be beneficial. Neurol Genet 2017;3:e183; doi: 10.1212/NXG.0000000000000183

\section{GLOSSARY}

ADHD = attention deficit hyperactivity disorder; $\mathbf{A T X P C}=$ ataxia-pancytopenia; $\mathbf{m f E R G}=$ multifocal electroretinography; HSCT $=$ hematopoietic stem cell transplantation .

Ataxia-pancytopenia (ATXPC; MIM 159550) syndrome is an autosomal dominant disease with early-onset gait and balance impairment, nystagmus, mild pyramidal signs, and marked cerebellar atrophy. Hematological abnormalities in ATXPC include pancytopenia, which may remain subclinical but can cause severe infections or hemorrhages. Through different genetic mechanisms in blood cells, the hematopoietic phenotype may be reverted. Elimination of the germline SAMD9L mutation by loss of chromosome $7(\mathrm{q})$ can result in myeloid malignancies. ${ }^{1}$

\footnotetext{
From the Sections of Neurology (S.G., C.N., A.P.), Pediatric Neurology (K.N.), Ophthalmology (S.A., U.K.), Pediatric Oncolocgy and Hematology (D.T., U.T., J.D.), Otorhinolaryngology (M.K.), and Hematology (L.N.), Department of Clinical Sciences, Skåne University Hospital, Lund University, Sweden; Department of Children and Adolescents (J.K.-E., J.U.), Department of Diagnostic Radiology (M.S.-P.), Department of Neurology (J.K.), and Department of Clinical Genetics, (E.R.), Oulu University Hospital; PEDEGO Research Unit (J.K.-E., E.R., J.U.), Medical Research Center Oulu (J.K.-E., M.S.-P., E.R., J.K., J.U.), Biocenter Oulu (J.K.-E., J.U.), and Research Unit of Clinical Neuroscience (J.K.), University of Oulu, Finland; Department of Hematology (J.C.), Linköping University Hospital and IKE Linköping University (J.C.), Sweden; and Division of Molecular Hematology (J.D.), Institution for Laboratory Medicine, Lund University, Sweden.

Funding information and disclosures are provided at the end of the article. Go to Neurology.org/ng for full disclosure forms. The Article Processing Charge was funded by the authors.

This is an open access article distributed under the terms of the Creative Commons Attribution-NonCommercial-NoDerivatives License 4.0 (CC BY-NC-ND), which permits downloading and sharing the work provided it is properly cited. The work cannot be changed in any way or used commercially without permission from the journal.
} 
Figure 1 Pedigrees of the Swedish and Finnish families with Ataxia-pancytopenia syndrome and SAMD9L mutations

A

I

18
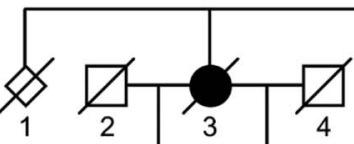

4
Family 1

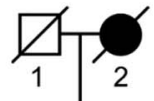

B

I

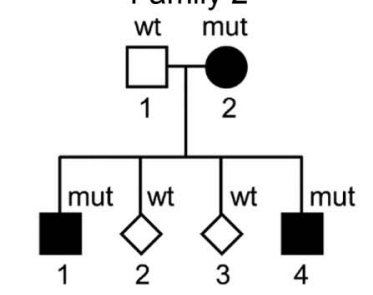

III

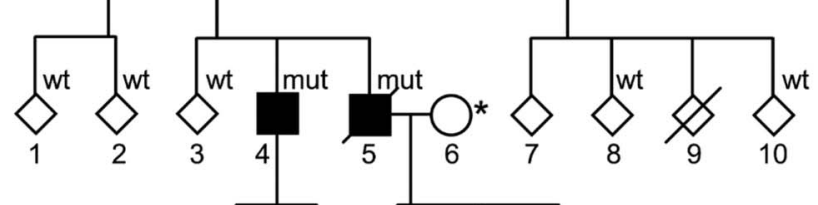

IV

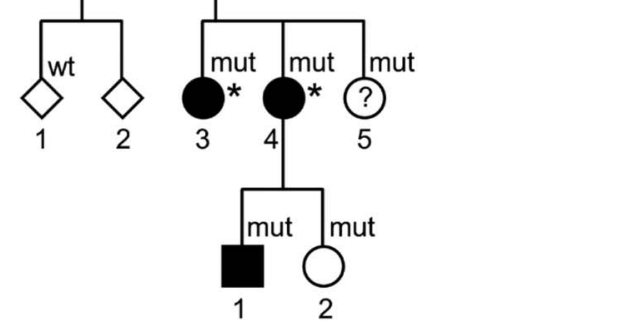

Standard symbols are used. Several members' sex is disguised (diamond-shaped symbols) and some family members are not included for reasons of confidentiality or lack of consent for this study. Solid symbols indicate neurologic signs or symptoms. (A) Family 1 (Swedish): mut: heterozygote SAMD9L c.2956C > T, p.Arg986Cys mutations in DNA from buccal swabs. Wt: wild-type. Asterisk (*): 3 individuals also carry the rare variant c.689C $>$ A p.Thr233Asn, located in trans in IV3 and IV-4. The c.2956C > T mutation leads to a gain of function of SAMD9L's inhibitory functions on cell-cycle regulation, whereas c.689C $>$ A was hypothesized to ameliorate this effect through a loss of function. (B) Family 2 (Finnish): mut: heterozygote SAMD9L c.2672T>C, p.lle891Thr mutations. Wt: wild-type in DNA extracted from the peripheral blood.

ATXPC has so far been described in 5 families, ${ }^{1-5}$ including the Swedish family (F1) and Finnish family (F2) reported here. Recently, missense mutations in sterile alpha motif domain-containing protein 9-like (SAMD9L) have been identified as the cause of ATXPC in 4 of these families. ${ }^{1,5}$ Following the genetic discovery, we studied the neurologic phenotype in F1 and F2.

METHODS Affected and unaffected family members of both families were examined by a neurologist. A structured interview and examination were performed including all clinical features previously described in ATXPC families, ${ }^{2-5}$ and the Scale for the assessment and rating of ataxia. ${ }^{6}$ Neuroradiologic images were compiled. Eye movement examination was filmed and reviewed by a neuro-otologist. Medical records were obtained whenever possible. Results of previous blood cell counts were reviewed, and new blood samples were taken. DNA was extracted using standard methods from the peripheral blood or buccal swabs. ${ }^{1}$ Some of the genetic analyses and clinical (hematologic) information have previously been published. ${ }^{1}$ For this study, F1 was expanded; newly included family members were tested with a custom droplet digital PCR TaqMan genotyping assay for the SAMD9L c.2956C $>$ T mutation (primers available on request). Two patients underwent detailed ophthalmologic examination, including optical coherence tomography, full-field electroretinography, and multifocal electroretinography (mfERG; appendix e-1 at Neurology.org/ng).

Standard protocol approvals, registrations, and patient consents. This study was approved by the responsible regional ethical standards committees. Informed consent was obtained from all participants.

RESULTS Data were compiled from 21 members of $\mathrm{F} 1$ and 6 members of F2. The pedigrees, individual neurologic phenotype, and $S A M D 9 L$ genotype are shown in figure 1 and table, and patient descriptions in appendix e-1 and videos $1-3$. DNA was obtained from 18 members of F1 and 6 members from F2. All mutation carriers who were examined within this study showed neurologic signs except the 4-year-old mutation carrier, F1: V-2, who had no obvious neurologic signs or symptoms according to her parents. Individual F1: IV-5 declined participation. Thirteen family members were examined who were subsequently shown not to carry $S A M D 9 L$ mutations; these did not have neurologic signs or symptoms.

F1: III-4 presented at our neurology clinic at age 53 years because of mild balance problems and a positive family history (figure 1). No SAMD9L mutation 


\begin{tabular}{|c|c|c|c|c|c|c|c|c|c|c|c|c|c|}
\hline Table & Immary of the neurologic phenotype of $A$ & ГXPC wit & SAMD9L mu & ations & & & & & & & & & \\
\hline ID: ref & SAMD9L mutation(s) & $\mathrm{AE} / \mathrm{AD}$ & Balance & Dysm & Dysart & Nystag & Strab & Retina & Pyram & Sens & Cog/beh & Cytopenia & MD \\
\hline F1: I-2 & ND & $80^{\mathrm{a}}$ & $++<55$ & NA & NA & NA & NA & - & NA & NA & - & NA & - \\
\hline F1: II-3 & ND & $87^{a}$ & $+++<53$ & + & + & GEN & NA & + & NA & NA & - & - & - \\
\hline F1: III-4 ${ }^{1}$ & $\begin{array}{l}\text { c.2956C }>\text { T, p.Arg986Cys } \\
\text { ('nonhematopoietic cells/buccal swabs only) }\end{array}$ & 64 & ++15 & + & + & GEN & - & PRD & AC, Bab, LEHR & Vibr & - & P; Neu & - \\
\hline F1: III-5 ${ }^{1}$ & c. $2956 \mathrm{C}>\mathrm{T}$, p.Arg986Cys & $58^{a}$ & + & NA & - & NA & NA & + & NA & NA & - & $\mathrm{R}, \mathrm{P}, \mathrm{L} ; \operatorname{Inf}$ & MDS (56) \\
\hline F1: IV-3 ${ }^{1}$ & $\begin{array}{l}\text { c.2956C }>\text { T, p.Arg986Cys; } \\
\text { c.689C }>\text { A, p.Thr233Asn }\end{array}$ & 38 & + & - & - & DBN & + & - & LEHR & - & - & - & - \\
\hline F1: IV-4 ${ }^{1}$ & $\begin{array}{l}\text { c. } 2956 \text { C }>\text { T, p.Arg986Cys; } \\
\text { c. } 689 \text { C }>\text { A, p.Thr233Asn }\end{array}$ & 33 & + & - & - & GEN, DBN & - & PRD & LEHR & - & - & - & - \\
\hline F1: IV-5 ${ }^{1}$ & c. $2956 C>$ T, p.Arg986Cys & 28 & NA & NA & NA & NA & NA & & NA & NA & - & $\mathrm{tR}, \mathrm{tP}, \mathrm{tL}$ & - \\
\hline F1: V-1 ${ }^{1}$ & c. $2956 \mathrm{C}>\mathrm{T}$, p.Arg986Cys & 6 & $++\left(4^{c}\right)$ & + & - & V & - & - & LEHR, S, Bab, AC & - & - & $R, P, L$ & MDS (4) \\
\hline F1: V-2 ${ }^{1}$ & c. $2956 C>T$, p.Arg986Cys & 4 & - & NA & NA & NA & NA & NA & NA & NA & - & $\mathrm{tP}$ & - \\
\hline F2: $1-2^{1}$ & c.2672T>C, p.lle891Thr & 34 & $+(32)$ & + & - & GEN, DBN & - & NA & LEHR, LLW & - & $\mathrm{LI}, \mathrm{MI}, \mathrm{ADHD}$ susp & $t P ; \operatorname{lnf}$ & - \\
\hline F2: $\| 1-1^{1}$ & c.2672T>C, p.lle891Thr & 14 & $+(5)$ & - & - & - & - & NA & - & - & ADHD & $\mathrm{tR} ; \operatorname{lnf}$ & \\
\hline F2: $11-4^{1}$ & c.2672T>C, p.lle891Thr & 9 & $++(7)$ & + & - & $\mathrm{H}$ & - & NA & LEHR, LLW, ppv & - & ADHD (4) & $\mathrm{R}, \mathrm{P}, \mathrm{L} ; \ln f$ & $\operatorname{MDS}(1,5)$ \\
\hline $1-1^{2,3,5}$ & c.3587G >C, p.Cys1196Ser & 54 & +++ adol & + & + & $\mathrm{H}$ & + & NR & AC, Bab & Vibr & - & NR & - \\
\hline $11-1^{2,3,5}$ & c.3587G>C, p.Cys1196Ser & $10^{\mathrm{a}}$ & ++ child & NR & NR & NR & + & NR & NR & NR & - & $\mathrm{Neu}$ & AML (10) \\
\hline $11-2^{2,3,5}$ & c.3587G >C, p.Cys1196Ser & $5^{a}$ & ++ child & NR & NR & NR & + & NR & NR & NR & - & R, P, L; Hem, Inf & - \\
\hline $11-3^{2,3,5}$ & c.3587G >C, p.Cys1196Ser & $9^{a}$ & ++ & NR & NR & $\mathrm{V}+\mathrm{H}$ & + & $\mathrm{NR}$ & NR & NR & - & $\mathrm{R}, \mathrm{Neu} ; \mathrm{Inf}$ & - \\
\hline $11-4^{2,3,5}$ & c.3587G>C, p.Cys1196Ser & 54 & ++ adol & + & + & $\mathrm{V}+\mathrm{H}$ & NR & NR & Bab & Vibr & - & $\mathrm{R}$ & - \\
\hline $11-5^{2,3,5}$ & c.3587G >C, p.Cys1196Ser & $7^{a}$ & +++ child & + & NR & V & + & NR & NR & NR & - & $R, P, L$ & AMMoL (7) \\
\hline UW-AP II-3 ${ }^{5}$ & c.2640C >A, p.His880Gln & $79^{a}$ & ++45 to 50 & NR & NR & NR & $\mathrm{NR}$ & NR & NR & NR & $\operatorname{dem} 69$ & Hem & - \\
\hline UW-AP II-4 ${ }^{5}$ & c. $2640 \mathrm{C}>\mathrm{A}$, p.His880Gln & $85^{\mathrm{a}}$ & +62 & + & + & $\mathrm{V}+\mathrm{H}$ & NR & NR & Bab, LEHR & NR & - & $\mathrm{P}$ & - \\
\hline UW-AP III-3 ${ }^{5}$ & c. $2640 \mathrm{C}>\mathrm{A}$, p.His880Gln & 60 & +30 & + & + & $\mathrm{H}>\mathrm{V}$ & NR & NR & AC, LEHR & NR & - & $\mathrm{R}, \mathrm{P}, \mathrm{L}$ & - \\
\hline UW-AP III- $5^{5}$ & c. $2640 \mathrm{C}>\mathrm{A}$, p.His $880 \mathrm{Gln}$ & $16^{a}$ & -16 & NR & NR & NR & NR & NR & NR & NR & - & $R, P, L ;$ Hem & - \\
\hline UW-AP III- $6^{5}$ & c. $2640 \mathrm{C}>$ A, p.His880Gln & 55 & ++25 & + & +++ & $\mathrm{V}+\mathrm{H}$ & NR & NR & AC, LEHR & NR & - & NR & - \\
\hline UW-AP III-8 ${ }^{5}$ & c. $2640 \mathrm{C}>\mathrm{A}$, p.His880Gln & 50 & +25 & + & NR & $\mathrm{V}+\mathrm{H}$ & NR & NR & AC, Bab, LEHR & NR & - & NR & - \\
\hline UW-AP IV-1 ${ }^{5}$ & c. $2640 \mathrm{C}>\mathrm{A}$, p.His880Gln & 32 & -18 & + & - & $V+H$ & NR & NR & AC, LEHR & NR & - & - & - \\
\hline UW-AP IV-2 ${ }^{5}$ & c. $2640 \mathrm{C}>\mathrm{A}$, p.His880Gln & 30 & -16 & + & - & $\mathrm{V}+\mathrm{H}$ & NR & NR & - & NR & - & $\mathrm{R}, \mathrm{P}, \mathrm{L}$ & - \\
\hline UW-AP IV-35 & c. $2640 \mathrm{C}>\mathrm{A}$, p.His $880 \mathrm{Gln}$ & 25 & -11 & + & - & $\mathrm{H}$ & $\mathrm{NR}$ & NR & AC, LEHR & NR & - & $R, P, L$ & - \\
\hline
\end{tabular}




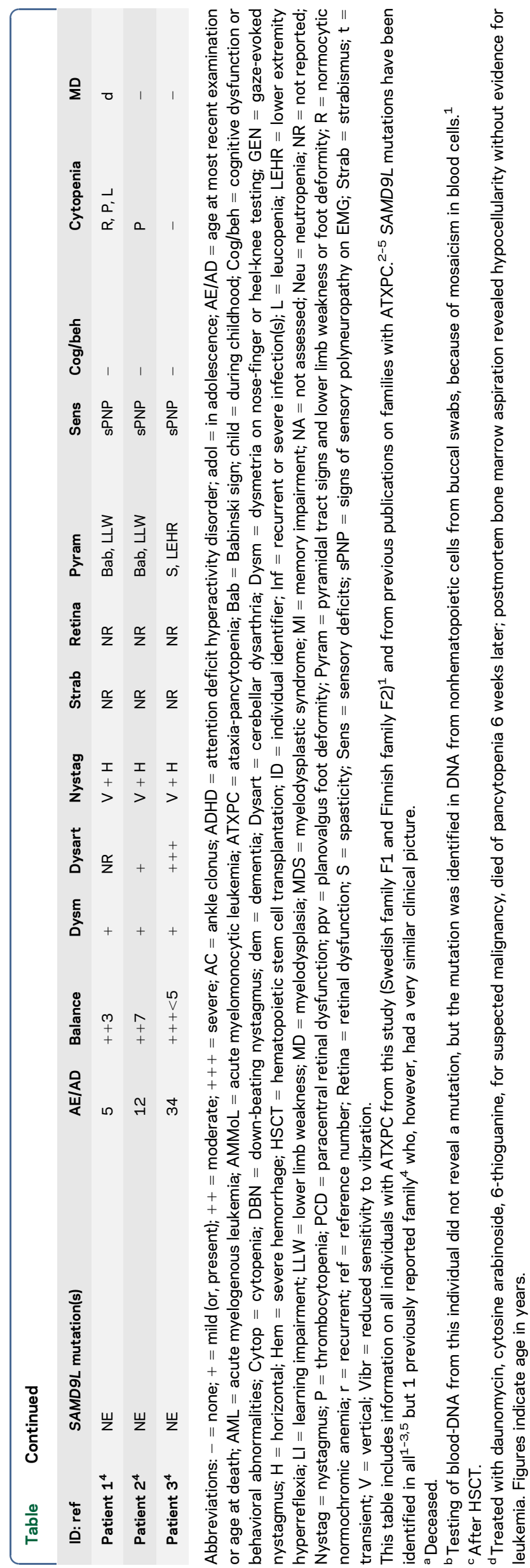

was identified in DNA from the peripheral blood, but nonhematopoietic cells from buccal swabs carried heterozygous SAMD9L c.2956C > T (p.Arg986Cys) mutations. ${ }^{1}$ His mother and maternal grandmother had similar symptoms that had progressed slowly. None of the other members of this family sought medical attention because of neurologic or ophthalmologic symptoms, but on direct inquiry, all patients examined reported mild balance impairment, for example during sports, and problems with gaze fixation.

F2: II-4 was referred to a pediatric neurologist at the age of 7 years after a single seizure during sleep. He had balance impairment, nystagmus, dysmetria, brisk Achilles tendon reflexes and muscle stiffness in the lower limbs. Symptoms had developed during the last months. His mother, F2: I-2, was investigated at the same time at the age of 32 years by a neurologist for memory problems, nystagmus, lower limb weakness, and balance problems. His brother, F2: II-1, had mild neurologic symptoms. The neurologic phenotype within the family ranged from nearly normal to marked disability. As described previously, a heterozygous SAMD9L c.2672T $>\mathrm{C} \quad$ (p.Ile891Thr) mutation was identified in DNA from the peripheral blood from all three affected individuals. ${ }^{1}$

The hematologic disorders of the family members have been described. ${ }^{1}$ Transient or permanent cytopenia was detected in 8 of 12 patients. Two children underwent hematopoietic stem cell transplantation (HSCT) because of myelodysplastic syndrome at 2 and 4.5 years. One of these patients $(\mathrm{F} 1: \mathrm{V}-1)$ had no neurologic symptoms prior to HSCT, but 3 months later, ataxic gait and nystagmus were noted. Similar treatment did not lead to neurologic worsening in F2: II-4, in whom follow-up MRI showed decreasing white matter abnormalities (figure $2 \mathrm{~B}$, appendix e-1).

F1: III-4 had noticed difficulties with gaze fixation during several years, and sometimes experienced difficulty reading or tendency to manual clumsiness, for example, when dining. Also, he sometimes found it cumbersome to see in conditions with low ambient light, such as during dawn, dusk, or in foggy weather conditions. Examination by mfERG, which reflects cone function in the posterior pole, demonstrated a reduction of paramacular cone function (figure 2C). In F1: IV-4, there was similar but milder paracentral retinal dysfunction. Other patients from both families reported very similar symptoms.

DISCUSSION The neurologic phenotype of ATXPC with $S A M D 9 L$ mutations is characterized by nystagmus and slowly progressive balance impairment. These signs were found in almost all SAMD9L mutation carriers examined in this study (table). The 

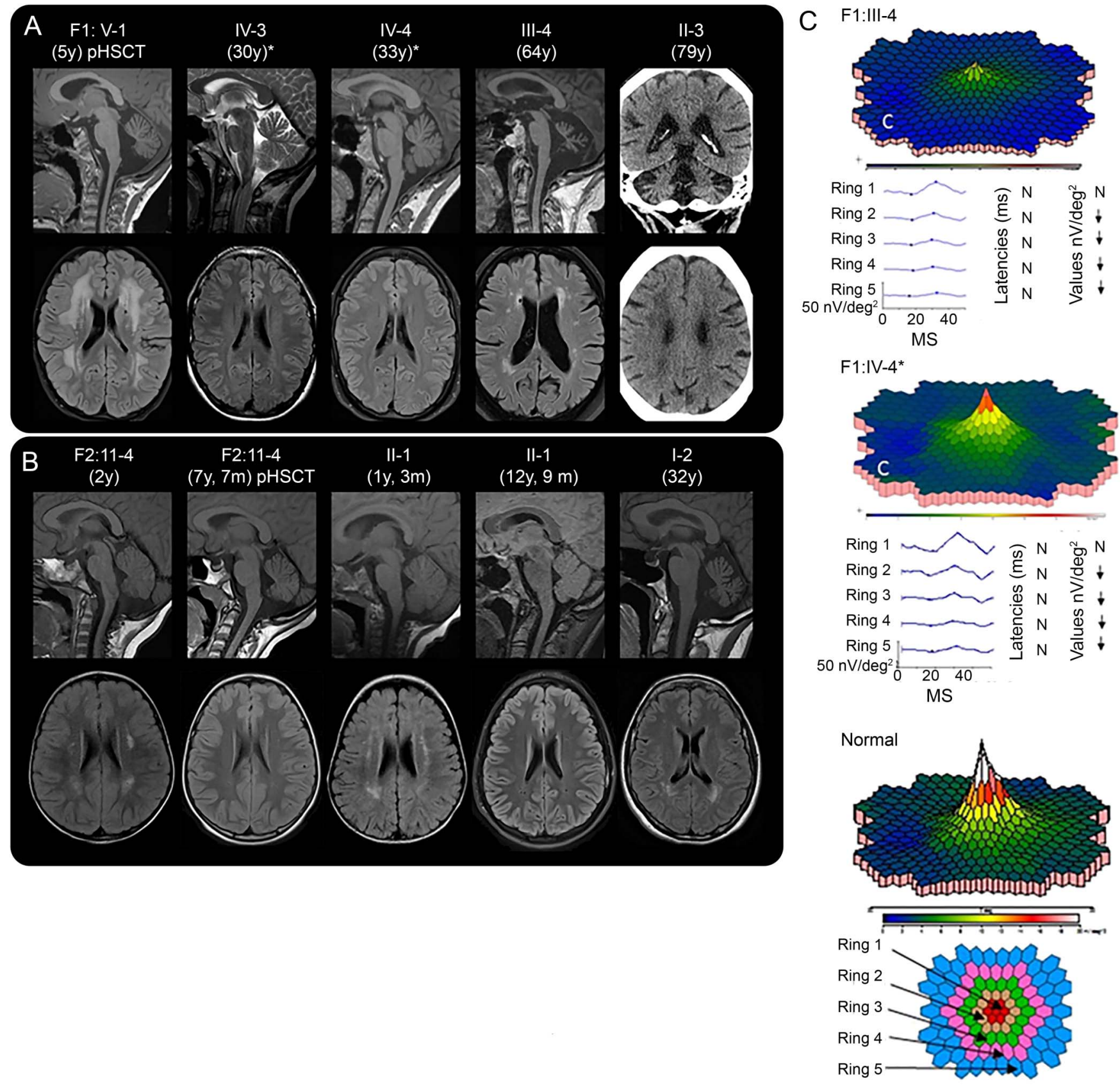

(A and B) Neuroradiologic findings in affected members of family 1 (A) and family 2 (B). Age at examination is provided in parentheses. pHSCT, examination performed posthematopoietic stem cell transplantation for hematologic malignancy. *Also carry the rare variant $S A M D 9 L$ c.689C $>A$ in trans. Sagittal MRIs reveal cerebellar atrophy in all individuals examined in adult age. Patient F1: V-1 had cerebellar atrophy at 5 years of age, (A) but patient F2: II-1 did not have clear cerebellar atrophy at 5 years of age (not shown). Later, at the age of 12 years and 9 months F2: II-1 and F2: II-4 at the age of 7 years and 7 months, both had mild cerebellar atrophy (B). Bilateral hyperintense signal changes were visible in the frontoparietal periventricular white matter on T2-FLAIR images to a variable degree in all patients, except the 2 adults with the rare variant SAMD9L c.689C $>A$ (A and B). Frontoparietal white matter changes of F2: II-4 and F2: II-1 decreased during childhood (B). F1: V-1 showed the most prominent white matter changes after hematologic malignancy and 3 months post-HSCT (A), but the white matter changes in F2: II-4, who also had hematologic malignancy and HSCT, decreased (B). For F1: V-1, the follow-up examinations 9 and 21 months post-HSCT showed unchanged widespread white matter abnormalities (not shown). FLAIR images revealed white matter abnormalities in the peritrigonal area in the individuals examined at 5 years and younger $(B)$ that might be a sign of incomplete myelination normal to this age (see appendix e-1). Since there were also peritrigonal white matter signal abnormalities in the adult patient F2: I-2 (B), they might indicate vulnerability of these areas in SAMD9L-related ATXPC. CT of patient F1: II-3 showed cerebellar atrophy and diffuse periventricular hypodensities of the cerebral white matter (A). (C) mfERG of 2 patients, compared to normal findings in an adult, shows reduced paracentral function in both patients, to a different degree. $N$, normal; $\downarrow$, significantly reduced function. Fundus photography and optical coherence tomography showed normal results (appendix e-1). ATXPC = ataxia-pancytopenia; FLAIR = fluid-attenuated inversion recovery; ms and MS, milliseconds. 
neuro-otological findings indicate midline cerebellar dysfunction. Balance impairment was clearly visible on examination, ${ }^{6}$ but it was mild or very mild in some patients with only difficulty with tandem walking or standing in a tandem position. Additional signs include mild pyramidal signs, strabismus, and decreased vibration sense. Neuroimaging revealed marked cerebellar atrophy in all 8 patients and periventricular white matter changes in 6 of 8 (figure 2). Attention deficit hyperactivity disorder or cognitive problems were noticed in 4 patients, but it remains uncertain if these are related to the disorder.

Ophthalmological symptoms or signs have not previously been described for ATXPC with SAMD9L mutations. Adult patients from both families reported reading and focusing difficulties. mfERG showed intact function in the most central area but marked paracentral (cone) dysfunction, which correlates with these visual symptoms. Similar ophthalmologic findings have been reported, for example, in patients with SCA7. . We suggest that some of the "atactic" signs in the upper extremities noted in patients with $S A M D 9 L$ mutations may in fact be caused by a decrease in visual control of hand movements, rather than cerebellar ataxia.

In our as well as all previously reported families, all carriers of pathogenic SAMD $9 L$ mutations developed neurologic signs. Expressivity was variable from individuals experiencing marked balance impairment to those who only noticed mild problems with balance or gaze fixation. Careful neurologic examination, however, revealed clearly abnormal signs in all carriers with complete penetrance. The hematologic disorders in members of both families have previously been described in detail. ${ }^{1}$ In these and the other families, there was pancytopenia with a risk of severe hemorrhages or infections on the one hand, and myelodysplastic syndrome on the other hand, but these hematologic abnormalities were not noticed in all mutation carriers (table).

One of SAMD9L's roles is that of a tumor suppressor or inhibitor of uncontrolled cell division. ${ }^{8}$ There is strong evidence that the disease-causing mutations exert a gain-of-function mechanism, resulting in more pronounced inhibition of cell division, which in blood cell lineages causes pancytopenia and genetic pressure to eliminate the mutant copy of the SAMD9L gene. ${ }^{1}$ Also in ataxia-telangiectasia, cerebellar degeneration co-occurs with immunologic deficiencies, lymphopenia, and increased risk of lymphoid malignancies. ${ }^{9}$ While dysfunction of DNA repair caused by mutations in ATM underlies some of the features of ataxia-telangiectasia, the cause of cerebellar degeneration in ataxia-telangiectasia remains difficult to explain. Perhaps similar to SAMD9L, ATM also influences cell-cycle signaling and cellular homeostasis pathways and interacts with another tumor suppressor, p53, in the cell-cycle control system. ${ }^{10}$ Cerebellar Purkinje cells and retinal cells might be particularly vulnerable to the effect of SAMD9L mutations.

\section{AUTHOR CONTRIBUTIONS}

Sorina Gorcenco: drafting/revising the manuscript for content, including medical writing for content, study concept or design, analysis or interpretation of data, acquisition of data, and other: examination of 13 adult patients, chart review. Jonna Komulainen-Ebrahim: drafting/revising the manuscript for content, including medical writing for content, analysis or interpretation of data, and other: clinical data on 2 Finnish pediatric patients. Karin Nordborg: drafting/revising the manuscript for content, including medical writing for content, analysis or interpretation of data, and other: clinical data on 1 Swedish pediatric patient and sibling. Maria Suo-Palosaari: drafting/revising the manuscript for content, including medical writing for content, analysis or interpretation of data, and other: neuroradiologic data on 3 Finnish patients and interpretation of neuroradiologic data. Sten Andréasson: drafting/revising the manuscript for content, including medical writing for content, analysis or interpretation of data, acquisition of data, obtaining funding, and other: ophthalmologic examination of 2 adult patients and evaluation of results. Johanna Krüger: drafting/revising the manuscript for content, including medical writing for content, analysis or interpretation of data, and other: clinical data on 1 adult patient. Christer Nilsson: revising the manuscript for content and other: clinical data on Swedish index patient (1 patient). Ulrika Kjellström: drafting/revising the manuscript for content, including medical writing for content, analysis or interpretation of data, and other: ophthalmologic examination of 2 adult patients. Elisa Rahikkala: revising the manuscript for content, including medical writing for content, analysis or interpretation of data, and other: genetic and genealogical studies of Finnish family, consenting. Dominik Turkiewicz: drafting/revising the manuscript for content, including medical writing for content, and clinical data on HSCT treatment of 1 Swedish pediatric patient. Mikael Karlberg: drafting/revising the manuscript for content, including medical writing for content, analysis or interpretation of data, and other: review of videos of eye movement examination. Lars Nilsson: revising the manuscript for content and other: contact with adult hematology patients. Jörg Cammenga: revising the manuscript for content and other: providing data on hematologic phenotype. Ulf Tedgård: drafting/revising the manuscript for content, including medical writing for content, analysis or interpretation of data, study supervision or coordination, and other: clinical data and contact with Swedish pediatric patient and sibling. Josef Davidsson: revising the manuscript for content, analysis or interpretation of data, acquisition of data, and other: genetic analyses of additional Swedish family members. Johanna Uusimaa: revising the manuscript for content, study concept or design, analysis or interpretation of data, study supervision or coordination, obtaining funding, and other: study supervision and coordination in Finland, interpretation of results, and ethical approvals (Finland). Andreas Puschmann: drafting/revising the manuscript for content, including medical writing for content, study concept or design, acquisition of data, study supervision or coordination, obtaining funding, and other: examination of 13 patients and ethical approvals (Sweden)

\section{ACKNOWLEDGMENT}

The authors thank the members of the 2 families who participated in the study. Research nurse, Emma Pettersson, coordinated patient visits in Lund, Sweden.

\section{STUDY FUNDING}

This study was supported by ALF, Skåne University Hospital research grants, and Cancerfonden, all Sweden.

\section{DISCLOSURE}

S. Gorcenco has received research support from ALF, Sweden and Skåne University Hospital research grants (Sweden). J. Komulainen-Ebrahim 
has received research grants from the Alma and K.A. Snellman Foundation (Oulu, Finland) and Finnish Cultural Foundation, North Ostrobothnia Regional Fund. K. Nordborg, M. Suo-Palosaari, S. Andréasson, and J. Krüger report no disclosures. C. Nilsson has received travel funding/speaker honoraria from the Movement Disorder Society; has served on the editorial board of the Journal of Neurodegenerative Diseases; and has received publishing royalties from Norstedts. U. Kjellström and E. Rahikkala report no disclosures. D. Turkiewicz has received a research grant from Barncancerfonden. M. Karlberg has served as an unpaid scientific advisor to Synphora AB (Stockholm, Sweden); has received payments from AstraZeneca AB (Sweden), Medical Need AB (Sweden), and Interacoustics A/S (Denmark, Sweden, Norway, and Finland) for lectures and instructional courses; and has been a consultant for Sensorion Pharmaceuticals SA (France). L. Nilsson reports no disclosures. J. Cammenga has received research support from Barncancerfonden, ALF, Skåne University Hospital (Sweden), and Cancerfonden. U. Tedgård reports no disclosures. J. Davidsson has received research support from ALF, The Swedish Society for Medical Research, and The Swedish Childhood Cancer Foundation. J. Uusimaa reports no disclosures. A. Puschmann has received travel funding/speaker honoraria from International Parkinson and Movement Disorder Society, Scandinavian Movement Disorder Society, International Association of Parkinsonism and Related Disorders, and Swedish Movement Disorder Society (SWEMODIS); serves as an editorial board member of Parkinsonism \& Related Disorders and BMC Neurology; has been a consultant for Swedish National Board of Health and Welfare; has received research support from ALF, Region Skåne, Trolle Wachtmeister Stiftelse, and Parkinsonfonden; and has received institutional support from MultiPark - a Strategic Research Environment at Lund University, and Skåne University Hospital research grants (Sweden) for neurogenetics research. Go to Neurology.org/ng for full disclosure forms.

Received May 2, 2017. Accepted in final form July 21, 2017.

\section{REFERENCES}

1. Tesi B, Davidsson J, Voss M, et al. Gain-of-function SAMD9L mutations cause a syndrome of cytopenia, immunodeficiency, MDS and neurological symptoms. Blood 2017;129:2266-2279.

2. Li FP, Potter NU, Buchanan GR, Vawter G, Whang-Peng J, Rosen RB. A family with acute leukemia, hypoplastic anemia and cerebellar ataxia: association with bone marrow C-monosomy. Am J Med 1978;65:933-940.

3. Li FP, Hecht F, Kaiser-McCaw B, Baranko PV, Potter NU. Ataxia-pancytopenia: syndrome of cerebellar ataxia, hypoplastic anemia, monosomy 7 , and acute myelogenous leukemia. Cancer Genet Cytogenet 1981;4:189-196.

4. Daghistani D, Curless R, Toledano SR, Ayyar DR. Ataxiapancytopenia and monosomy 7 syndrome. J Pediatr 1989; 115:108-110.

5. Chen DH, Below JE, Shimamura A, et al. Ataxia-pancytopenia syndrome is caused by missense mutations in SAMD9L. Am J Hum Genet 2016;98:1146-1158.

6. Schmitz-Hubsch T, du Montcel ST, Baliko L, et al. Scale for the assessment and rating of ataxia: development of a new clinical scale. Neurology 2006;66: $1717-1720$.

7. Hugosson T, Gränse L, Ponjavic V, Andréasson S. Macular dysfunction and morphology in spinocerebellar ataxia type 7 (SCA 7). Ophthalmic Genet 2009;30:1-6.

8. Wang Q, Zhai YY, Dai JH, Li KY, Deng Q, Han ZG. SAMD9L inactivation promotes cell proliferation via facilitating G1-S transition in hepatitis B virus-associated hepatocellular carcinoma. Int J Biol Sci 2014;10:807-816.

9. Rothblum-Oviatt C, Wright J, Lefton-Greif MA, McGrath-Morrow SA, Crawford TO, Lederman HM. Ataxia telangiectasia: a review. Orphanet J Rare Dis 2016;11:159.

10. Shiloh Y, Ziv Y. The ATM protein kinase: regulating the cellular response to genotoxic stress, and more. Nat Rev Mol Cell Biol 2013;14:197-210. 


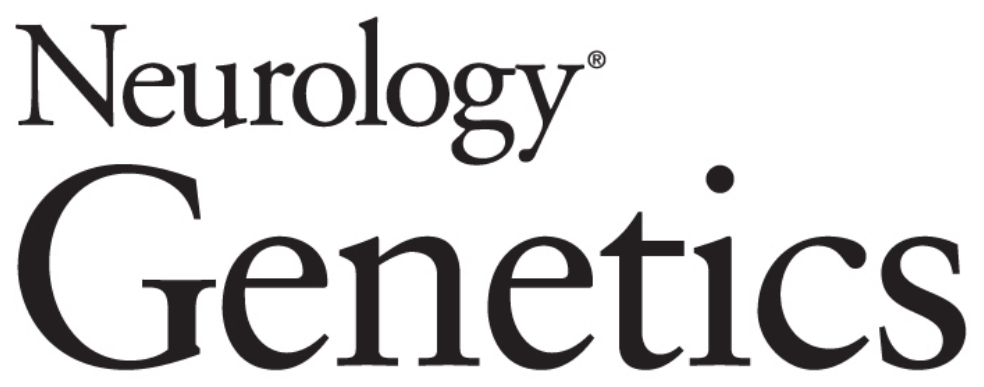

Ataxia-pancytopenia syndrome with $S A M D 9 L$ mutations

Sorina Gorcenco, Jonna Komulainen-Ebrahim, Karin Nordborg, et al. Neurol Genet 2017;3;

DOI 10.1212/NXG.0000000000000183

This information is current as of August 24, 2017

Neurol Genet is an official journal of the American Academy of Neurology. Published since April 2015, it is an open-access, online-only, continuous publication journal. Copyright Copyright ( 2017 The Author(s). Published by Wolters Kluwer Health, Inc. on behalf of the American Academy of Neurology.. All rights reserved. Online ISSN: 2376-7839.

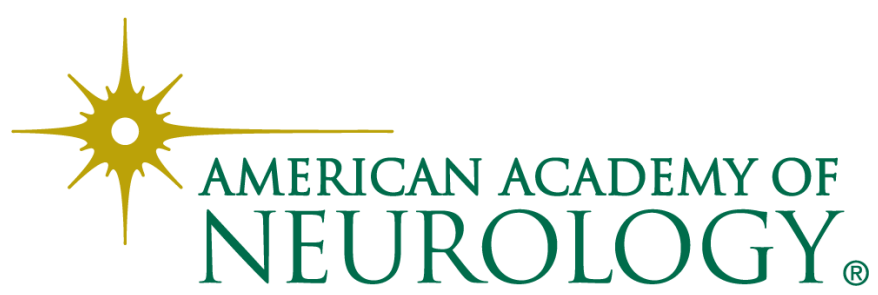




\section{Updated Information \& Services}

\section{Supplementary Material}

\section{References}

Citations

Subspecialty Collections

Permissions \& Licensing

Reprints including high resolution figures, can be found at: http://ng.neurology.org/content/3/5/e183.full.html

Supplementary material can be found at: http://ng.neurology.org/content/suppl/2017/08/24/3.5.e183.DC1

This article cites 10 articles, 1 of which you can access for free at: http://ng.neurology.org/content/3/5/e183.full.html\#\#ref-list-1

This article has been cited by 5 HighWire-hosted articles: http://ng.neurology.org/content/3/5/e183.full.html\#\#otherarticles

This article, along with others on similar topics, appears in the following collection(s):

\section{All Genetics}

http://ng.neurology.org//cgi/collection/all_genetics

Cerebellum

http://ng.neurology.org//cgi/collection/cerebellum

Gait disorders/ataxia

http://ng.neurology.org//cgi/collection/gait_disorders_ataxia

Nystagmus

http://ng.neurology.org//cgi/collection/nystagmus

\section{Retina}

http://ng.neurology.org//cgi/collection/retina

Information about reproducing this article in parts (figures,tables) or in its entirety can be found online at:

http://ng.neurology.org/misc/about.xhtml\#permissions

Information about ordering reprints can be found online:

http://ng.neurology.org/misc/addir.xhtml\#reprintsus

Neurol Genet is an official journal of the American Academy of Neurology. Published since April 2015, it is an open-access, online-only, continuous publication journal. Copyright Copyright ( 2017 The Author(s). Published by Wolters Kluwer Health, Inc. on behalf of the American Academy of Neurology.. All rights reserved. Online ISSN: 2376-7839.

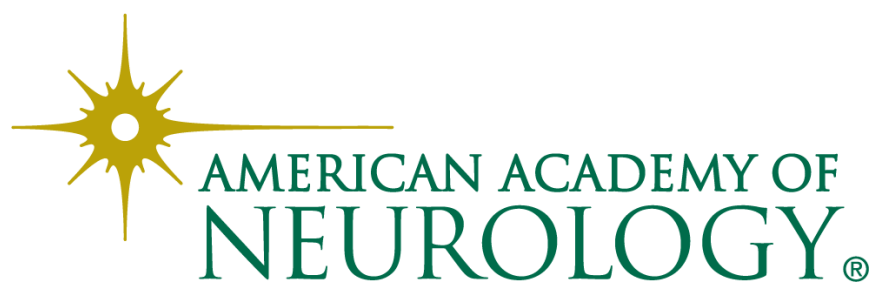

